\title{
Putting the Gender Back in Digital Housekeeping
}

\author{
Jennifer A. Rode \\ UCL Institute of Education \\ London, United Kingdom \\ jen@acm.org
}

\author{
Erika Sheenan Poole \\ Pennsylvania State University \\ Pennsylvania, United States of America \\ erika.s.poole@gmail.com
}

\begin{abstract}
Prior work examining technology usage and maintenance practices in homes describes division of labor in terms of technical expertise. In this paper, we offer a counter-narrative to this explanation for engagement with Ubiquitous Computing. Using feminist theory as an analytic lens, we examine how gender identity work is a determining factor of whether and how people engage with digital technologies in their homes. We present a model of gender \& technical identity co-construction.
\end{abstract}

\section{CCS CONCEPTS}

\section{- Human-centered computing $\rightarrow$ Human computer interaction $(\mathrm{HCl})$}

\section{KEYWORDS}

\author{
Gender, Privacy, Security, Networking, Human- \\ Computer Interaction, Ubiquitous Computing, Sex, \\ Technical Ability, Self-Efficacy, Agency. Idenity
}

\section{ACM Reference format:}

Jennifer A. Rode and Erika Sheenan Poole. 2018. Putting the Gender Back in Digital Housekeeping. In Proceedings of 4th Gender\&IT Conference, Heilbronn, Germany, May 2018 (GenderIT'18), 10 pages.

https://doi.org/0001.00001.10

\section{INTRODUCTION}

Our research on gender emerged out of our studies of the home situated in the fields of ubiquitous computing and human computer interaction. Digital Housekeeping is our term for the use of these domestic ubiquitous computing technologies; it is the activity one does in the smart home often using the Internet of Things. In this

\footnotetext{
Permission to make digital or hard copies of part or all of this work for personal or classroom use is granted without fee provided that copies are not made or distributed for profit or commercial advantage and that copies bear this notice and the full citation on the first page. Copyrights for third-party components of this work must be honored. For all other uses, contact the owner/author(s).
}

paper, we looked at digital housekeeping including issues with setup, usage, and maintenance of domestic technology. We examine the particularly complex, interconnected technologies which become part of the fabric of everyday domestic life. We ask, what encourages individuals to engage in digital housekeeping? Prior work describes division of labor of these tasks such that the home forms a "domestic economy," [48] where the division of labor only discusses the role of expertise - such that the most technologically literate person in the home becomes the de facto maintainer. Here we investigate emergent patterns regarding gender and labor.

It became evident through our research that the Information Science literature as demonstrated by Trauth's review [56] has been tackling gender, however, in the HCI literature in the home this was not the case. An overwhelming portion of the studies on domestic technology do not consider the role of gender [49]. More broadly, Barkhuus and Rode [4] report a failure of publications in HCI to even document the gender of the participants on which the test new technologies. More recently, we have seen a call for feminist HCI $[2,47]$. However, this is a somewhat insular body of literature largely independent of the Information Science community, illustrated by how Trauth's literature review on gender in IS research did not cover these publications. Just as Trauth [56] has called for a need to "explicitly employ" gender theory on IS, in relation to HCI, Rode has made similar calls for how the gender identity(ies) of participants needs to be recorded and that the gender theory used as an analytical framework for grounded theory, must be discussed.

In this paper we explore alternative factors in these divisions of labor, specifically the role of gender. To do so, we use feminist theory to synthesize two previously published studies of digital housekeeping in light of gender identity work. We demonstrate how gender identity work can serve as an alternative analytical treatment of digital housework - one that is not only organized around technical ability, but also identity work. Our findings inform the design of future domestic ubiquitous computing technologies, as well as outreach efforts aimed at increasing

(C) 2018 Copyright held by the owner/author(s). 123-4567-24-567/08/06 . . \$15.00 DOI: $x x x$ 
diversity in computing. We contribute by proving a socio-technical gender model for exploring influences between gender and technology during design.

\section{RELATED WORK}

For over a decade, human-computer interaction researchers have studied the role of information technologies in domestic life, exploring routines of use [10,37, 55], effects of life disruptions on usage [15, 34, 46], divisions of labor [21, 22, 42, 46, 48], collocated gameplay [60], communication [26, 27], and coordination [13, 36, 52]. While there is some discussion of the

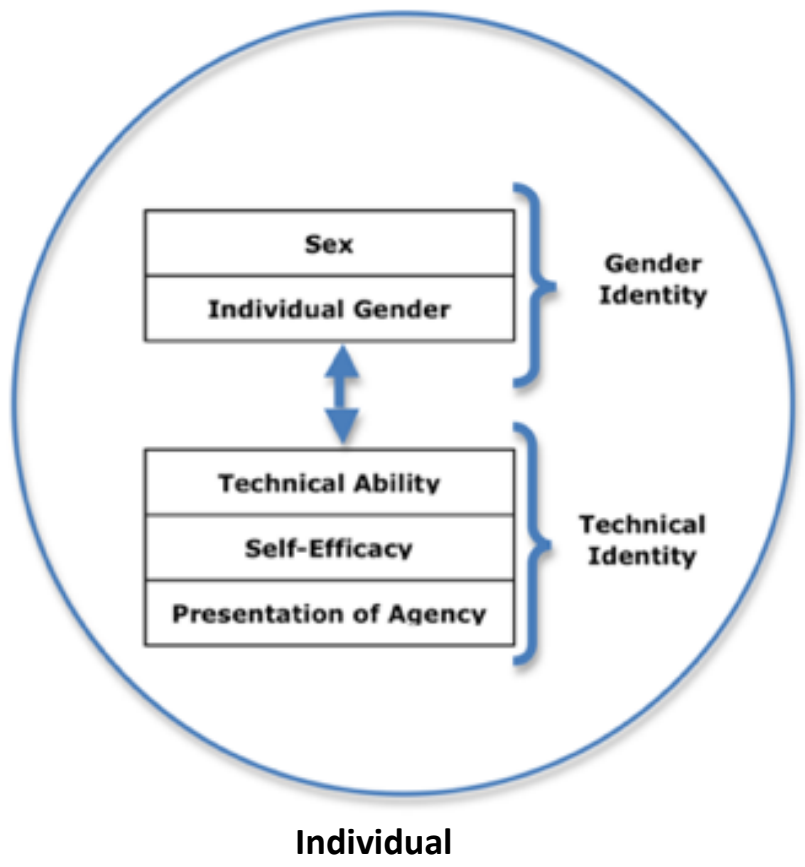

Consequently, according to this perspective, technology design is inherently biased by male power and interests [11], and reflects culturally dominant idealized masculine norms (commonly referred to as hegemonic masculinity), such as independence, aggression, risk-taking, heterosexuality, and rationality [9]. This suggests women may actively choose to reject technology, present themselves as non-technical, or experience what scholars call gender inauthenticity, a term for feeling a mismatch between feminine gender identity and demonstrating technical competency [57]. Gender inauthenticity, while it originates with Turkle [58], has been core to the more recent feminist theories of Faulkner

\section{Figure 1. The Socio-Technical Gender Model for the Co-Construction of Gender and Technical Identity.}

gendered nature of engagement with technology in homes $[3,5,36]$ digital housekeeping, gender has been a carefully sidestepped (perhaps even taboo?) topic. Yet given the longstanding scholarship on the gendered nature of non-digital forms of housework $[18,19,30,33,50,53]$ we find this gap to be surprising. Like Bardzell and Bardzell [2], we take the stance that feminism provides a lens for technology critique and aim to make such a critique with respect to digital housekeeping.

A range of literature focuses on how women negotiate involvement with technology while still maintaining their gender identity. A school of thought in feminist scholarship referred to as technology as masculine culture takes the perspective that there will continue to be a tension between gender identity and technical identity as long as numbers of male engineers exceed female ones.
[17] and Henwood and et al [24].

Perhaps most relevant to this perspective is Kvande who provides examples of how female engineers construct their

gender and technical identities relative to the hegemonic masculinity of corporate engineering firms [28]. Women in Kvande's study were confronted with a "dilemma of difference" [28], a decision on how to behave and dress at work. They face the challenge of self-presentation. Should they make themselves more or less visible as women by adhering to or deviating from normative gender norms. To frame this work, Kvande relied upon sameness/difference theory. Sameness/difference theory emerged as a feminist response to authors such as Betty Friedan, who explored the legal and social implications of women working outside the home. American Legal scholar Catharine A. 


\section{Putting the Gender Back in Digital Housekeeping}

\author{
Gender\&IT'18, May 2018, Heilbronn, Germany
}

MacKinnon explained the core resulting ideological problem with sameness/difference; enlightenment thought argues for gender equality as a type of "sameness," and yet its definitions of sex assume "difference" [32]. Given prior to women's suffrage in 1920, American laws were entirely written by men, men were and to a large extent still are the default legally given two hundred-odd years of legal precedence [32]. Thus, within a legal context, legislation has codified equality between men and women, but in the process, women being "equal to" men can be conflated as women being "the same" as men. Feminist scholarship has used sameness/difference theory to examine ways in which women who follow male norms regarding dress and comportment adopt "sameness" strategies, whereas women who conform to societal norms of feminine behaviors engage in "difference" strategies [32, $51,61]$. In other words, men are the normative standard against which women are measured, a standard that can break down in cases such as pregnancy or any other instance where their difference becomes apparent. Here we explore this theories relevance for HCI within the highly gendered context of technology.

We acknowledge sameness/ difference theory is not without its critics. Queer theorists such as Judith Butler [9] argue against heteronormativity, a term for society's assuming strict male and female gender roles along with heterosexual relationships. Further, she argues gender is not a strict male/female binary, rather gender expression can be fluid. One significant critique of sameness/ difference theory by Queer theorist, Catharina Landstrom is that have expressed it ignores the complex, and potentially fluid nature of an individual's gender identity, or identities [29]. We acknowledge the seriousness of this critique; to address this we treat gender as a continuum using heteronormative sameness and difference strategies as reference points, while at the same time considering the space between them to be fluid. This approach allows people to construct multiple identities along the continuum, for instance a woman might have a more masculine technical persona at work and yet try to evoke a feminine sameness strategy at home. Finally, in our attempt to construct a non-binary treatment of sameness \& difference theory we do not privilege heteronormativity, rather we are using it only as a reference point for our discussion.

Kvande, while acknowledging that sameness/ difference theory may lead to uniform, homogenous categories that may not account for complexity of gender, uses the framework to identify four broad approaches women used to negotiate their gender and technical identities in the workplace (These four categories were as follows: the homeless, compensators, challengers, and 'one of the boys' women). Kvande's four categories were intended for the office, and do not cleanly transfer to domestic settings. That said this strategy of using sameness and difference as an analytical lens is highly relevant and as such we endeavored to create comparable domestic categories. Categorizing women's behavior relative to a masculine behavior norm may seem somewhat culturally regressive, but in a male dominated field such as computing [12, 16, 56], sameness/difference theory can provide new insights into how people structure their gender identities. We extend use of this theory from corporations $[17,28]$ to the domestic environment. The notion of sameness is highly relevant in that it is a way of resolving gender inauthenticity, whereas difference strategies challenge and subvert gender inauthenticity. Thus, using the sameness/difference approach, we specifically examine how women construct their structural gender around symbolically gendered technologies, and by doing so demonstrate the importance of feminist theory as an analytic treatment for Ubicomp.

While the sameness and difference debate focuses on women only, here we have used this approach to code male behavior relative to masculine norms as well. In doing so this allows us to engage with the household as a unit of analysis with its complex and enmeshed gender constructions. Therefore, men's behavior in line with structural gender norms (for example a man protecting his partner by installing anti-virus software) is coded as a sameness strategy, whereas behavior deviating from norms is coded as a difference strategy. We feel this is an appropriate extension given our interest in avoiding heteronormative gender constructions. This allows us to also consider male difference strategies, allowing consideration of feminine identities.

\section{OUR MODEL}

Next, we will discuss our our Socio-Technical Gender Model for the Co-Construction of Gender and Technical Identity . Throughout the course of this research through a dialogue with our data we arrived at model that describes the relationship between the individual and society in terms of how they negotiate both their gender identity as well as their technological one. Borrowing from Bijker [8] who discusses "...the concept 'technological frame' a hinge between the social impact and the social shaping perspectives on technology" (p98). We argue gender and technical identity are co-constructed with one another and are similarly mutually constitutive. Next, we will present this model, and in later sections we will present the study and the findings that allowed us to arrive at it.

\subsection{The Individual}

To discuss gender and technological identity at the individual level one must consider both gender and technical identity.

\section{Gender Identity}

One's gender at an individual level is a critical element of our model. Gender is a nuanced, multi-faceted concept [17]. When one speaks of gender, one may be referring to his or her personal affiliation and identity, typically referred to as gender identity [9, 23] and we will use this term throughout. We have selected this term to build on Harding's vocabulary which differentiates individual gender from symbolic and structural gender (which we will define shortly in the societal section of the model). While this term is somewhat similar to Trauth's individual gender, Trauth focuses on how a "woman's demographic and professional characteristics affect her career choices" [56]. How an individual 
thinks of one's gender may include those aspects, but could also be structured independently of them. We frame individual gender in line with Butler's treatment [9] in that it can be fluid.

\section{Technical Identity}

At an individual level we also see an individual's technical identity which we argue is comprised of their Technical Ability, SelfEfficacy and their Presentation of Agency.

Technical Ability: Technical ability refers to technical knowledge that is independent of action. Note that what one knows technically and how confident one appears to others regarding technology are two different things. A person could, for example, be quite knowledgeable yet lack confidence and vice versa [25].

Self-Efficacy: Self-efficacy refers to one's self-predicted likelihood of success at a task. Prior research demonstrates the importance of self-efficacy to gaining proficiency in technical domains such as end-user programming [5] is core to understanding End-User Programming because of its link to tinkering. "Females should be encouraged to tinker because it helps them to be effective, with the important caveat that tinkering in a complex environment carries a risk of damaging the females' self-efficacy" [5]. Self-efficacy as defined by Beckwith measures an individual's confidence, an internal cognitive state, making it a difficult characteristic or trait to assess [5]. Appearance of confidence may differ from internal, experienced confidence as we have the ability to pretend that we feel differently than we really do. As with technical ability, a person may have self-efficacy with respect to a given task but choose to hide it from others for any number of reasons.

Presentation of Agency: Independent of ability and self-efficacy is agency. Agency as Giddens writes is a property representing an individual's capacity to engage in action and is a "continuous flow of conduct" [20]. Regardless of one's actual abilities, or confidence in one's abilities, presentation of agency involves how one presents these abilities and accepts or denies responsibility for one's actions [39]. One could own one's technological successes, which result from skill; one could own one's technological successes that result from luck. One could consciously disavow one's success; or one could deny success without conscious intent. Each of these is an example of negotiating presentation of agency. Presentation of agency can make it difficult to determine a person's true selfefficacy.

Our use of presentation of agency stems from Ortner [38] who discusses how her American informants tended to "change the subject" when they are asked to discuss topics related to class. By changing the subject, she does not mean so colloquially, but rather in the semantic sense. She is saying women are attributing their actions to others. However, she then immediately broadens her usage of how people "change the subject". In the same way Ortner argues that class can contribute to agency, we argue that gender is a contributing factor to women failing to recognize their own agency as it relates to the their technology successes. The woman in Ortner's example may have agency, but by "changing the 4 subject," she demonstrates she does not recognize her own ability to engage in and direct her actions-- she fails to recognize her own agency. Women negotiate their presentation of their technical agency, along with their actual Technical Ability and gender presentation. Further, this negotiation of presentation of technical agency is done in concert with Structural Gender. An assertion of technical agency by a female member of a household could be perceived as a direct rebuff of digital chivalry and a diminishment of the masculinity of her partner. As such, this gendered negotiation is a complex constellation of goals and considerations.

\subsection{Society}

The term gender is it is often overloaded and refers to gendering at of the individuals, objects and society. This is ripe for confusion. Thus, in addition to Harding's Individual Gender we use her Symbolic and Structural Gender.

Symbolic Gender: Symbolic gender can refer to an identity or property ascribed to objects $[6,59]$ or built environments, or nature [31, 39].

Structural Gender : Structural gender [23] refers to normative practices of labor division in society [18, 31, 39], referred to as. Individual gender can be gender fluid, but very often society constructs structural and symbolic gender in fashions that reify binaries, thus when we use the terms masculine or feminine we do so with full awareness that these identities allow for a limited space of gender expression. These layered meanings of gender interact with one another as individuals manage their relationships with technology.

\subsection{Interactions: Individual and Society}

This model demonstrates on how an individual and societal level there is mutual bi-directional influence, a gendered version of Bijker's technological frame [8]. These examples demonstrate how each aspect of this model are critical to understanding how technology is created, appropriated, and used.

We argue gender and technical identity are co-constructed. They do not occur in isolation. Rather at an individual level individual gender and technical identity influence one another. Further, one's individual gender and structural gender practices of society bi-directionally impact one another. Similarly, an individual's technical identity and society's symbolic gendering of objects also bi-directionally impact one another.

We introduce this model and the complex terminology as it allows for a richer and more nuanced vocabulary gender than is present in the current literature.

\section{METHODS}

We illustrate this model with two distinct studies of domestic technology setup, usage, and maintenance practices in North American homes. Both explored divisions of labor, articulation work, and help-seeking practices with one exploring security and 


\section{Putting the Gender Back in Digital Housekeeping}

Gender\&IT'18, May 2018, Heilbronn, Germany privacy related strategies used by 19 households [46] and the other networked device setup and maintenance in 10 homes [41]. Both studies were part of our $\mathrm{PhD}$ dissertations. Consequently, both studies are from 2008 and 2009. The data being 'dated' does not preclude it illustrating this model which represents a novel contribution. Further, given the clear historical pattern that adopting new technology for housework results in increased cleanliness and standards, but does not reduce time savings for women [50, 53], we feel even historic technology use serves as a good predictor of future technology adoption patterns.

The differences between these studies reflect the trajectories of existing independent research activities additionally prior publications focused on creating taxonomies of the types of technical work and coordination done in home [42, 43, 45]. None of the prior publications stemming from these dissertations specifically focused on the role of gender in digital housekeeping, thus our model is a novel contribution. Next, we discuss the study's methods, their methodological and disciplinary differences. These reflect differences in the authors' training.

We asked no questions regarding sexual orientation of our participants. Most of our participants were in heterosexual marriages, or mentioned opposite sex lovers, thus we believe they were largely straight. We know of only one LGBTQIA identified person in our sample. At the same time, we are analyzing this data using queer theory. This is not an incongruous approach in that queer theory can be used as a starting point to analyze any data set regardless of sexual orientation.

\subsection{Study 1: Security and Privacy Support}

Study 1 examined household practices surrounding information security and privacy (see [45, 49] for fuller details of the study including detailed demographics). Households were recruited in 2007 via a prominent software company's customer lists and snowball sampling. The homes were located in Silicon Valley $(n=11)$ and greater Los Angeles areas $(n=8)$ of California, United States. In total, 50 individual interviews were conducted across all of the sites. Although this area of the United States has a reputation of early adoption of information technologies, anthropologists have noted that studies of cultural elites can be instrumental for understanding practices by non-elites [35].

Rode conducted this research while employed at a private security company in Silicon Valley. This firm paid Rode to conduct a study of on privacy practices in the home, with an understanding she would use the data in this analysis on gender identity. Data were collected via ethnographic methods. Computer safety and security were discussed an in-home dinner with the research team, interviews with household members, and participant-led 'home tours' in which they showed the researchers technology artifacts related to computer safety and security. Memos were generated by the researchers, and data were analyzed using grounded theory techniques [54].

\subsection{Study 2: Network Setup and Maintenance}

Study 2 examined setup, maintenance, and help-seeking practices in homes using networked information technologies [40, 42]. Ten households in a major metropolitan area of a southeastern United States city were recruited in 2010 through a marketing research firm $(n=7)$ and snowball sampling $(n=3)$. In contrast to Study 1, these participants were not early adopters of information technologies; but instead late adopters, purchasing items when their life situation deemed it necessary (e.g. a previous device failed), or acquiring items for free through one's workplace, from donations of old equipment from family or friends, or as gifts.

Over a three-week period, each family set up, configured, used, and sought help from people within their friends and family regarding common home electronics and information technologies that prior studies have shown to be problematic (described more in $[22,41])$. The participants also installed and used a piece of custom software for collaborating and managing knowledge about their home computing environments.

Data were collected via group and individual interviews, questionnaires, software logs, and written responses in logbooks. Households participated in a group interview and home tour at the beginning of the study. At the conclusion of this session, the research team provided a set of technology-related 'homework' assignments to complete over the week, which served as breaching experiments to uncover information about technological divisions of labor in the home [41]. Each week, the research team visited each home studied, conducted a short check-in interview with each household member, collected logbooks, and provided a new set of homework for the upcoming week. At the conclusion of the study, the household members completed a questionnaire, were interviewed as a group, and were interviewed individually.

Across all ten homes, the research team collected 35 transcribed interviews, 191 photographs, and copious field notes written after each home visit. Qualitative data were analyzed using affinity diagramming [7]. These findings were triangulated against survey and software log data collected from each home.

\subsection{Analytical Framework for this Paper}

Both studies employed grounded theory as a method of analysis, as in our larger body of unpublished work gender had emerged as a key theme. The larger unpublished body of work from Study 1 used grounded theory to arrive at two key axial codes. The first category was strategies for household role allocation; we lay these strategies out in section 4 of this paper. The second category is how one negotiates the presentation of gender identity along a masculine or feminine spectrum. This axial coding was then applied to Study 2, and the codes were refined. Of course, grounded theory needs to rest on and advance a theoretical framework. Our axial coding was supported by sameness/difference theory, Butler's critique of heteronormativity [9] and Bijker's technological frame [8]. We used Kvande [28] and Day's [14] discussions of normative gendered patterns of behavior as a basis of comparison for our data. We have combined these theories in an interdisciplinary way, 
creating a multi-faceted lens for viewing gendered technology interactions.

\section{FINDINGS}

Households in both studies used three different approaches to allocate technology roles and responsibilities: 1) having a technology czar, a person who ran the show technically; 2) relying upon self-support within the household; and 3) relying on outsidesupport providers. We summarize each of these approaches in turn (see [45] for detailed definitions of terms).

\subsection{Gender and Technical Identity}

Therefore, when we speak of technical identity, we are referring to how people choose to show self-efficacy, how they present agency, and how they have acquired technical abilities. It can be argued whether decisions about gender identity and technical identity are conscious or subconscious, but in either case, they are negotiations in response to hegemonic norms associating power with technology, technology with masculinity, and avoidance or fear of technology with femininity [11]. Men and women enact these roles as they decide how and when to engage with technology.

In the following pages, we show how people make strategic decisions as to how to present their technical abilities and gender, thus co-constructing their gender and technical identities. Note that we are not suggesting that our findings will necessarily apply to all people in all situations, or are rigid prescriptions of how men and women should engage with technology; rather we are reporting what we observed in the context of our two studies, neither of which had upfront, explicit goals of studying gender identity construction. We discuss how households in our studies did not merely divide the labor of digital housekeeping tasks in terms of skill. Often, familial relationships are forged around ideals of male power and control as expressed through 'technology' and female nurturance of the families using technologies that are defined as feminine [44]. Power and nurturing are key components of structural gender around technology, thus technical identity and gender identity are key subjects of renegotiation of gendered divisions of labor. In the next sections, we first discuss how men used sameness and difference strategies to construct masculinity. Following that, we turn to how women used sameness and difference strategies to construct femininity.

\subsection{Constructing Masculinity in Relation to Technology}

\subsubsection{Constructing Masculinity: Sameness Strategies.}

If femininity is constructed as the absence of the masculine, and women are a relational concept only identifiable in a state of change, then masculinity itself must be constantly reaffirmed [1]. We illustrate this by comparing our data to architect and feminist scholar Kristen Day's theory. She looks at how gender identity construction manifests in public space in daily life [14]. She argues there are two strategies that can be used by men to reaffirm their masculinity, which can be applied to gender roles around digital housekeeping. First, by showing off strength and generally acting like a "bad-ass" with other men, they are able to reinforce their masculinity [14]. With women, however, this behavior has a negative effect; the second masculinity-reaffirming strategy is use of chivalry (attentive, courteous, and honorable behavior towards women). While perhaps Day's categorization uses a broad brush, her study of Irvine California shows how men-even in an extremely safe city - engaged in chivalric masculinity. She writes, "more than half the participants described women's fear in public spaces as either too little or as the 'right' amount. Men supported the idea of the city of Irvine and the University of California, Irvine public spaces as dangerous for women" [14]. Day's exploration of this dichotomy suggests that insisting that public spaces are dangerous affords men the chance to be chivalrous, thereby reinforcing their own desirability. Day argues men feel the need to and women allow themselves to be protected even when the crime statistics suggest protection was unnecessary [14].

Day's classification focuses solely on male-female interactions, and does not include instances where children are present. In those instances, chivalrous behavior towards women may be part of larger practices of good behavior. While one may disagree with Day's classification of potential ways of expressing masculinity, her work is important for two reasons. First, it illustrates that masculine norms are not static, but rather socially constructed. Secondly, it suggests chivalry might occur even when it is unnecessary for non-functional purposes, which presents an interesting possibility if applied to computers.

Next, we will explore this co-construction of masculine technical identity in each of its forms (technical ability, selfefficacy and presentation of agency), using sameness and difference theory. We identify the following categories of masculine participation: the chivalrous gentleman, the helpful (posturing) man, and the technical in other ways man. We did not observe any instances of men who disavow their technical identity completely although it is possible that this co-construction of gender and technical identity can occur.

We make the case that providing technological support may allow men an opportunity to demonstrate their masculinity in the home; being a technology czar is the digital equivalent of walking a woman home at night. In this case a man protects a women from untold dangers that lurk in the dark city or in the wilds of cyberspace. It affords a demonstration of chivalry and thus allows assertion of masculinity (-ies), in part through mastery of technological complexity. In both studies, the individuals providing support-whether or not they were members of the householdwere primarily male. While these individuals may not have spoken particularly of a need to protect their partners, their language focused on controlling the computer, including both the activities, and the people involved. Frank of household_W1's technology czar noted: "Nothing happens on it [the computer] that I didn't 


\section{Putting the Gender Back in Digital Housekeeping}

\author{
Gender\&IT'18, May 2018, Heilbronn, Germany
}

authorize...nothing comes off of it, nothing goes on to it". If masculine attitudes towards technology focus on control and mastery [30], and since control is a mechanism for achieving protection, it is not surprising that men would formulate their views of protection in these terms. In providing these computer support services, men reaffirm their own masculinity, because women reaffirm and ground their feminine identities in allowing men to control their computer use and protect them from cyberspace's dangers.

Note that digital chivalry does not equal technical expertise; in fact, we saw instances in which overly 'helpful' men provided help to others in their household without appropriate contextual or technical knowledge. For instance, the men in E3 and E10 would make technology changes that were not appropriate given the home's technical or social contexts.

\subsubsection{Constructing Masculinity: Difference Strategies}

For men, engaging in technology support for their homes represents a sameness strategy, and we saw few men deviate from it. When asked about the division of roles and responsibilities in the home, some members spoke to difference strategies at length while others made no comment. In the two households with female technology czars (E6, W14), the husbands engaged in the most radical difference strategy, justifying their technical ability (e.g. lack of participation was due to other constraints such as low attention span or preferences for 'mechanical' things). These wives also took efforts to justify their husbands' technical abilities in other realms, such as home and car repair.

This relationship is reciprocal. As Day reminds us, "women may also try to invoke chivalrous masculinity in men as part of women's own performance of gender identities" [14]. Consequently, even in households in which men did not remark on the difference strategy [32], the women did so on their partners' behalf. In home W3, Christina was the office manager responsible for procuring computer help from her company's IT department, yet she was careful to stress her dependence on IT despite doing many technical tasks herself.

Women's reliance on boyfriends as outside-support providers in outside-support households is testimony to the efficacy of this approach. Invoking chivalrous masculinity at the same time requires women's adherence to gender norms [14]. Consequently, gender inauthenticity was problematic for these women, as they justified their technical abilities at length.

Unfortunately, the specialization of a technology czar or outside-support provider presents a challenge for computer maintenance when household structure changes, or computer support providers leave individuals' lives. As Day [14] points out, "by calling on male protection, women reinforce traditional feminine identities that emphasize fragility and dependence." Women can lose access to their computer support provider when a relationship ends, be it due to the death of a partner or a relationship's end, as it has been noted in other work [14, 46]. For instance, in E7, a divorce thrust single mother Viola and her three daughters to take on all technology related tasks without the help of her former husband. Individuals came to rely on someone else being responsible for computer maintenance, a tenuous situation at best. This may potentially be a larger and more significant problem for women who come to depend on these providers only to lose them due to changes in household structure.

Day argues that this performance of masculinity and actions to protect women "may be only indirectly related to danger, and may effectively reduce women's freedom and independence in public space" [14]. Similarly, demonstrations of masculinity through digital housekeeping hamper women's mastery of technologyrelated tasks, leaving them vulnerable if changes in the domestic environment mean loss of the support provider. Women's allowing or encouraging digital chivalry, our phrase for gallant protection of women through information technology, might not stem from differences in interest or abilities, but as a means of negotiating gender structure as new technologies are introduced into the home.

\subsection{Constructing Femininity in Relation to Technology}

In the next section, we look at how women construct their femininity in relation to information technologies, and how these constructions relate to the sameness/difference strategies employed by men. The women in our studies had a range of different levels of technical abilities. Some were highly technical and felt their abilities were beyond comment; others interpreted their abilities in terms of parenting and housework; and others still denied their technological competence. In the following section, we will look at four sameness/difference strategies used by the women in our sample. We do not wish to argue that these approaches are mutually exclusive, nor do we wish to form a complete taxonomy of women's approaches to technology; instead, we hope to distinguish among the range of strategies we observed for technical and gender identity construction. These strategies may be complementary and may be used dependent on the situation. The presentation of one's technical ability may change between the work and the domestic setting. For instance, Kathy (W7) yet claimed that she does not engage in technology work at home despite performing it in the office. Further, the motivation for this might differ. A pragmatic division of labor may influence the presentation of one's technological ability, or it may be a desire to present oneself as more or less feminine. For example, Kathy could have been downplaying her technical ability to encourage her husband to do more work. Regardless, division of labor typifies normative definitions of domestic femininity. Thus, our aim is to discuss the range of strategies available to women for reconciling and constructing their gender and technical identities. In doing so we would like to stress the potential for a disconnection between actual technical ability, presentation of agency, and self-efficacy.

\subsubsection{Constructing Femininity: Sameness Strategies}

The first strategy women in our studies employed is being what we refer to as a geek. Women such as Kate (W2), Miranda (W16), and Kassandra (the daughter in E7) openly embraced their technological interests, keeping with masculine norms, without 
comment on them or their femininity, thus representing a sameness strategy. As outlined earlier, presenting as technically sophisticated is often challenging for many women, as interest in technology is often equated with negative stereotypes. Turkle's research characterizes geeks as comfortable with technology, thus having both high self-efficacy and willingness to show agency, but also as being avoidant of personal relationships, which can raise issues of gender inauthenticity [57]. Consequently, it raises the question of what aspects of these women's personality and backgrounds permit this sort of sameness strategy.

While a definitive answer merits further study, in looking at these women's backgrounds, it is perhaps unsurprising that they embraced their technological and gender identity without comment. All of the women had considerably more technical training and had received more mentoring than the others we interviewed. Kate holds a master's degree in software engineering from a top-tier technical university. Her professional background required her to negotiate her gender identity to include technological competency. Miranda similarly had a doctorate in a computationally related discipline. There technical education brought them in direct contact with masculine technical culture, and like Kvande's female engineers downplayed their differences from men to become 'oneof-the boys' and fit in [28] In the course of conversations these women, unlike others we interviewed, did not act defensively regarding their technical ability. This suggests less gender inauthenticity for this population. Being an engineer gave them a socially defined role in which they did not have to negotiate extensively to create a sameness strategy. Having an identity construction that can be labeled with established attitudes towards gender or technology, may have obviated the need for them to negotiate their gender or technical identity in daily conversation. Finally, while uncommon we also saw some evidence of women who were aspiring geeks - those who did not have much technical ability, but publicly displayed interest and identification with technology. Karen (E4), Kassandra (E7), and Adrian (E8) all met these criteria. While not having any sort of deep technological knowledge, they were avid users of social media and the Internet. For these women, computers were not in conflict with identities; rather they were yet another communication tool.

\subsubsection{Constructing Femininity: Difference Strategies}

We now turn to difference strategies used by women in our studies. By using difference strategies, they constructed their technical identity in accordance with societal norms regarding heteronormative gender identities. That is, unlike the geeks they did not downplay their femininity to ensure sameness with men. These strategies include the good woman, damsel in distress, and technophobe. It is not our intention to proscribe whether and how individuals choose to co-construct their gender and technical identities, but rather to describe behaviors observed and using terminology to aid discussion. These categories may initially seem heteronormative and stereotypical, but we urge the reader to consider them as archetypes providing foundations for identity work.

The first strategy we discuss is the good woman. We use good woman in the historic usage to mean one who is respectable, in the sense that she conforms to societal gender norms [23]. Women in this group had significant technical ability, yet during the interview constructed these abilities as part of the normative behavior of a 'good' homemaker, mother, widow, or daughter. This reference to the structural gender of typical female behavior allowed them to affirm their femininity while engaging with technology, thus they engaged in a difference strategy. Women in E1, E6, E8, W4, W5, W7, and W1 all exhibited such traits. They created a feminine definition of self and were able to actively seek out technological solutions for themselves, but couched them in terms of socially accepted normative gender roles.

For instance, Cindy (E1), was a teacher, a traditionally 'feminine' role. Cindy, despite being responsible for setting up and maintaining all technology within her household, downplayed her technical expertise. She stressed during the data collection sessions that she asked for technical advice and help from technically inclined male students in her classroom to give her remote technical advice.

A related approach is discussing technology in terms of division of labor within the home. Kathy's assertion was that she washes dishes and her husband does the computers (W7). Kathy had technical skill and performs a number of technical tasks around the house, but stated a preference for not doing technical work at home, "she can do it all at the office but... [but at home] I don't want to have to do tech," an attitude that allows her to leave her technical identity at work. By referring to a gendered division of domestic work, Kathy emphasizes that doing technical work is not her job at home, which also helps camouflage her actual abilities. During the interview, she explained she flirted with her husband to get this technical work done, implicitly appealing to digital chivalry. Additionally, her comments render her technical work invisible, which further strengthens the perception of gender structure. Through both of these approaches, Kathy is managing technical identity presentations so that does not challenge normative gender structure.

Barbara, the female technology czar of W14, took a different approach to maintaining her small network of Apple computers, and talked about her technology and security activities as "just another type of housework." For Barbara, cleaning the viruses from the computer was an extension of her role as a working mom who was accustomed to organizing her freelance consulting work around her parental and household responsibilities. This approach is indicative of Strasser's findings [53] that, as technologies are "domesticated," they are integrated into a woman's domestic role. In homes like Barbara's, women attempted to present their husbands as the more 'technical' person, and to redefine their own roles in terms of being working moms. 


\section{Putting the Gender Back in Digital Housekeeping}

Gender\&IT’18, May 2018, Heilbronn, Germany
In each of the households where good woman strategies were in effect, we see how women's work with technology was presented in terms of the normative gender structure. In presenting technology tasks as an extension of these normative roles, women were following a difference strategy. Each of these women worked with the men in their households to construct their husband or partner's gender and technological identities in a fashion that at minimum did not challenge their masculinity, and in some cases, still afforded him a chance to engage in digital chivalry.

These women engaged in redefining societal gender norms (gender structure) and gender ascribed to computing (symbolic gender) in response to the new technology. As new technologies are introduced, the appropriate amount of technical expertise that is part of a feminine ideal is being negotiated. In our study these women were attempting to ensure that use of these new technologies fell within the realm of normative feminine behavior. Over time, as new technologies become commonplace in the domestic realm, they lose their feminine status. As such, these technologies no longer challenge conceptions of an a-technological femininity, as seen with technologies such as the telephone and the radio [38]. Modern home computing may follow a similar trajectory. Consequently, these technologies over time may require less negotiation, as they may become femininely gendered, but for the moment these women were engaging in an effort to negotiate and interpret gender roles with regard to technology. The danger, however, is that like the radios, telephones, ovens and many technologies before, women's technical work will become invisible as it becomes symbolically gendered as feminine.

In the future, structural gender norms to which the good woman aspires may include computer-related maintenance, and technology support may be redefined as just another type of houseworksomething that is no longer masculine. Presently these roles are being negotiated, and gender authenticity for good women will continue to be a challenge requiring resolution. Good women on the one hand have agency, yet by working to make technology symbolically gendered female, they also undermine its status as (masculine) 'technology.' These households illustrate how technology use, agency, and significant technical abilities can be negotiated and presented in the form of normative behavior reaffirming femininity.

Another difference strategy, which we refer to as the damsel in distress, was used by women who de-emphasized their technical ability and actively sought out digital chivalry as a primary means of addressing their technology needs. In E1, E7, W8, W10, W11, and W19 men, including boyfriends, ex-boyfriends, ex-husbands, and brothers served as outside-support providers. As members of outside-support households, these women sought help with the selection of computers and major issues, yet took responsibility for the day-to-day computer housekeeping. By relying on men to solve some of their technology needs, they simultaneously allowed for displays of digital chivalry and re-affirmation of their feminine identity. A typical example was Lisa, whose boyfriend gave her a computer. He installed AVG, a free anti-virus program, which would not require an annual payment. She wanted to switch back to Norton, which she knew how to use, but she did not know how to remove AVG. Since it was a gift, she had to wait for an appropriate time to ask for additional help and socially negotiate the situation so as not to appear ungrateful. These women show agency by consciously encouraging digital chivalry. As discussed earlier in this paper, this situation presents a possibility for dependency and control. Still, these women achieved their technology goals with little gender inauthenticity and very little identity maintenance required.

The final difference strategy used was that of being a technophobe. While some women demonstrated agency without comment, and some carefully negotiated the presentation of their gender and technical identities, technophobic women attempted, either consciously or subconsciously, to project an image of being fearful or separate from technology. For instance, Deedra of E3 openly discussed being fearful and nervous around technology; for her being a mom was incompatible with being comfortable with technology. A related example is Christina of W3, who was concerned about protecting the security of her digital data. She was capable of pursuing a security strategy of her own-she wanted to get a Macintosh as she felt they were more secure - and yet she chose to adhere to the strategy of the males in her life, who were not interested in these types of computers. In line with Ortner [38], she is "changing the subject" and making herself appear to have less knowledge than she does. By rejecting her own technological knowledge, defining herself as a-technological, and reinforcing gendered division of work, she preserves her feminine identity. Through these actions, Christina removes a potential challenge to her feminine image and allows her husband to reinforce his masculine image through a display of digital chivalry. Consequently, women can use masculinely gendered technologies without challenging their feminine identity, as long as the women present themselves as having little agency in their use.

In this section, we have demonstrated four strategies women used for negotiating femininity and technology. We have shown that technical identity is complex and comprised of actual technical ability, presentation of agency, and self-efficacy, and that understanding true self-efficacy is difficult because it is filtered through presentation of agency. We have shown a range of approaches to how women negotiate agency with technology, and how they handle the potential for gender inauthenticity. However, we do not wish to argue that these approaches are mutually exclusive, nor do we wish to form a complete taxonomy of women's approaches to technology; instead, we distinguish among the range of strategies observed for identity construction.

Some women were engaged in a transition between gender identities for instance E10. Here Nyree lived separately from her husband with her children in a less expensive city, as they could not afford to all live where he was located. While she was a technophobe and relied on her husband and son for technical support, she also demonstrated independent proficiency, for instance setting up a printer as part of the study. Nyree showed marked improvement in her self-efficacy during the study. She also expressed a desire to have more knowledge to avoid her family 
unexpectedly changing things on her machine. As illustrated by this last transitional category, identity is not static, but rather coconstructed in response to changing circumstances.

\section{CONCLUSIONS: Theory \& Future Work}

Prior treatments of digital housekeeping in the ubiquitous computing literature framed division of labor in terms of tasks and ability with little discussion of the gendered nature of domestic work. In this paper, we have shown how gender identity and technical identity are co-constructed in the home, and how gender norms factor into selection of a range of sameness or difference strategies used. We have shown how men engage in sameness strategies such as being 'digitally chivalrous gentlemen', as well as, less skilled 'helpful' men. They also engage in difference strategies, stressing that lack of IT competence did not detract from being men who are 'technical in other ways'. Similarly, we have shown four approaches as to how women present agency with regard to technology in the home - the geek, the good woman, the damsel in distress, and the technophobe. We do not wish to argue these approaches are mutually exclusive, nor that this is complete taxonomy of gender and technology in the home; instead, we illustrate a range of ways we observed individual gender identity management. These approaches allow for a range of unique ways of presenting different levels of technical ability, self-efficacy, presentation of agency, and gender identity. Thus, we demonstrate a range of ways people negotiate agency with technology, and how they handle the gender inauthenticity.

Our case studies illustrate how critical theory around these aspects of gender structure allowed us to frame a discussion of various types of gender behavior. Understanding gendered patterns of domestic work is vital in understanding technology work in the home. Thus, based in our studies we contribute a model for the gendered co-construction of individual gender and technical identity in the context of social practices. An individual's gender identity(-ies) is comprised of a person's sex and gender, and does not rely on binary gender. Technical identity is comprised of technical ability, agency and presentation of agency. Each of these factors can vary in different contexts, as one's gender identity changes, one's technical skills grow, or one changes the aspects of oneself they are comfortable sharing with others. On a societal level, we must consider the structural gendering of technological work, and the symbolic gendering of technologies themselves. This model demonstrates on an individual and societal level there is mutual bi-directional influence, a gendered version of Bijker's technological frame [8]. We demonstrate how each aspect of this model are critical to understanding how technology is created, appropriated, used and changed.

With regards to the particular sameness and difference strategies we laid out for men and women, future research may introduce more nuances in approach, show how some of these methods are used in concert, or differentiate between the approach used with the casual stranger versus the long-time friend, lover, professional 10 colleague, or look at women or men who have different combinations of gender identity and technical ability. Regardless, this research makes the theoretical contribution that both men and women are co-constructing their gender and technical identities, and that technology is a symbolically gendered object around which this identity construction occurs.

We conclude with a call to arms that technology designers need to take these co-construction strategies into account. We are not arguing for more of the industry 'shrink it and pink it' approach to attract women, or that technology disengagement is merely a lack of expertise. Instead, we argue that overcoming the issue of women's disengagement with technology may require more nuanced solutions. Women's disengagement will be not be resolved merely through interventions such as early socialization with technical objects or providing child-friendly workplaces for women wishing to have technical careers [17] (that is not to say we do not support child-friendly workplaces as a key tool). We offer the above model of the co-construction of gender and technical identity in the individual and society as a nuanced model to ground such discussions. Technology needs to be designed to allow individuals to present a range of gender and technical identities to be inclusive to all.

We have demonstrated how technology is enmeshed in the creation and appropriation of gendered values, and we have presented our Socio-Technical Gender Model (See Figure 1). If during design we wish to ascribe social values to our technology, then we should encourage progressive attitudes towards gender roles, especially towards women, technology designers. Supporters of STEM diversity need consider how this process of coconstruction of gender and technological identity occurs. A first step is studies in Ubicomp, and HCI more broadly, discussing gender in these more nuanced terms. A deep understanding of Socio-Technical Gender practices will allow for the creation of technologies that support technology use for both men and women with a wide range of gender identities.

\section{ACKNOWLEDGMENTS}

We would like to thank our participants, Paul Dourish, Genevieve Bell, Beki Grinter, Keith Edwards, Nicola Marsden, Andrea Marshall, and Louise Barkhuus. We are especially indebted to the many, many reviewers of various drafts of this paper who contributed significantly to its refinement.

\section{REFERENCES}

[1] Linda Alcoff. 1988. Cultural Feminism Versus Post-Structualism: The Indentity Crisis in Feminist Theory. Signs 13, 3, 405-436.

[2] Shaowen Bardzell and Jeffrey Bardzell. 2011. Towards a Feminist Hci Methodology: Social Science, Feminism, and Hci. In Proceedings of Proceedings of the SIGCHI Conference on Human Factors in Computing Systems. ACM, Vancouver, BC, Canada, 675-684. http://dx.doi.org/10.1145/1978942.1979041

[3] Shaowen Bardzell, Shad Gross, Jeffrey Wain, Austin Toombs and Jeffrey Bardzell. 2011. The Significant Screwdriver: Care, Domestic 


\section{Putting the Gender Back in Digital Housekeeping}

Masculinity, and Interaction Design. In Proceedings of Proceedings of the 25th BCS Conference on Human-Computer Interaction. British Computer Society, Newcastle-upon-Tyne, United Kingdom, 371-377.

[4] Louise Barkhuus and Jennifer A. Rode. 2007. From Mice to Men - 24 Years of Evaluation in Chi. In Proceedings of Proceedings of the SIGCHI Conference on Human Factors in Computing Systems. ACM, San Jose, California, USA. http://dx.doi.org/10.1145/1240624.2180963

[5] L. Beckwith, C. Kissinger, M. Burnett, S. Widenbeck, J. Lawrance, A. Blackwell, and C. Cook Year. Tinkering and Gender in End-User Programmers $\times$ Debugging. In Proceedings of Proceedings of the $\mathrm{SIGCHI}$ conference on Human Factors in computing systems (CHI '06). ACM Press, 231-240.

[6] Anne-Jorunn Berg, and Merete Lie. 1995. Feminism and Constructivism: Do Artifacts Have Gender? Science, Technology and Human Values 20, 3, 332-351.

[7] H. Beyer, \& Holtzblatt, K. 1997 Contextual Design: Defining Customer-Centered Systems. Morgan Kaufmann., San Francisco, CA.

[8] W. E. Bijker. 1992. The Social Construction of Fluorescent Lighting, or How an Artifact Was Invented in Its Diffusion Stage In Shaping Technology/Building Society: Studies in Sociotechnical Change,

MIT Press, Cambridge, MA:, 75-104.

[9] Judith Butler. 2006. Gender Trouble. (3rd). Routeledge, New York.

[10] Marshini Chetty, Richard Banks, Richard Harper, Tim Regan, Abigail Sellen, Christos Gkantsidis, Thomas Karagiannis and Peter Key. 2010. Who's Hogging the Bandwidth: The Consequences of Revealing the Invisible in the Home. In Proceedings of Proceedings of the SIGCHI Conference on Human Factors in Computing Systems. ACM, Atlanta, Georgia, USA, 659-668. http://dx.doi.org/10.1145/1753326.1753423

[11] C. Cockburn. 1992. The Circuit of Technology: Gender, Identity and Power. In Information and Communication Technologies in the Home., Routledge, New York.

[12] H. G. Corneliussen. 2012. Gender-Technology Relations: Exploring Stability and Change. . Palgrave P., New York, New York: .

[13] Andy Crabtree and Tom Rodden. 2004. Domestic Routines and Design for the Home. Comput. Supported Coop. Work 13, 2, 191-220. http://dx.doi.org/10.1023/B:COSU.0000045712.26840.a4

[14] Kristen Day. 2001. Constructing Masculinity and Women's Fear in Public Space in Irvine, California. Gender, Place and Culture 8, 2, 109127.

[15] Jill P. Dimond, Casey Fiesler and Amy S. Bruckman. 2011. Domestic Violence and Information Communication Technologies. Interact. Comput. 23, 5, 413-421. http://dx.doi.org/10.1016/j.intcom.2011.04.006

[16] N. Ensmenger. 2010. . Making Programming Masculine. In In Gender Codes., T. J. Misa Ed. John Wiley \& Sons, Inc., Hoboken, NJ:.

[17] W. Faulkner. 2001. The Technology Question in Feminism: A View from Feminist Technology Studies. Women's Studies International Forum 24, 1, 79-95.
Gender\&IT’18, May 2018, Heilbronn, Germany

[18] C.S. Fischer. 1992. America Calling: A Social History of the Telephone. $\mathrm{U}$ of CA Press, Berkeley, Berkeley, Ca.

[19] V. Frissen. 1985. Gender Is Calling: Uses of the Telephone. In The Gender-Technology Relation; Contemporary Theory and Research. , K. Grint, and Gill, R. Ed. Taylor and Francis,, London.

[20] A. Giddens. 1979. Central Problems in Social Theory: Action, Structure, and Contradiction in Social Analysis. . University of California Press., Berkeley and Los Angeles, CA.

[21] Beki Grinter, Keith Edwards, Mark W. Newman, and Nicolas Ducheneaut. Year. The Work to Make a Home Network Work. In Proceedings of Proceedings of the ninth conference on European Conference on Computer Supported Cooperative Work. 469 - 488.

[22] Rebecca E. Grinter, W. Keith Edwards, Marshini Chetty, Erika S. Poole, Ja-Young Sung, Jeonghwa Yang, Andy Crabtree, Peter Tolmie, Tom Rodden, Chris Greenhalgh and Steve Benford. 2009. The Ins and Outs of Home Networking: The Case for Useful and Usable Domestic Networking. ACM Trans. Comput.-Hum. Interact. 16, 2, 1-28. http://dx.doi.org/10.1145/1534903.1534905

[23] Sandra Harding. 1986. The Science Question in Feminism. Cornell U P, Ithaca, NY.

[24] Karen L. Henwood, Karen Anne Parkhill and Nick F. Pidgeon 2008. Science, Technology and Risk Perception: From Gender Differences to the Effects Made by Gender. Equal Opportunities International 27, 8, 662-676. http://dx.doi.org/doi:10.1108/02610150810916730

[25] Chuck Huff. 2002. Gender, Software Design, and Occupational Equity SIGCSE 34, 2, 112-115.

[26] Tejinder K. Judge and Carman Neustaedter. 2010. Sharing Conversation and Sharing Life: Video Conferencing in the Home. In Proceedings of Proceedings of the SIGCHI Conference on Human Factors in Computing Systems. ACM, Atlanta, Georgia, USA, 655-658. http://dx.doi.org/10.1145/1753326.1753422

[27] Tejinder K. Judge, Carman Neustaedter, Steve Harrison and Andrew Blose. 2011. Family Portals: Connecting Families through a Multifamily Media Space. In Proceedings of Proceedings of the SIGCHI Conference on Human Factors in Computing Systems. ACM, Vancouver, BC, Canada, 1205-1214. http://dx.doi.org/10.1145/1978942.1979122

[28] Elin Kvande. 1999. 'In the Belly of the Beast;' Constructing Femininities in Engineering Organizations. The European Journal of Women's Studies 6, 305-328.

[29] C. Landstrom. 2007. Queering Feminist Technology Studies. Feminist Theory 8, 1, 7-26. http://dx.doi.org/10.1177/1464700107074193

[30] S Livingstone. 1992. The Meaning of Domestic Technologies: A Personal Construct Analysis of Familial Gender Relations. In Information and Communication Technologies in the Home., Routledge, New York.

[31] Carol MacCormack, and Marilyn Strathern. 1980. Nature, Culture and Gender (4th). Cambridge UP, Cambridge.

[32] MacKinnion. 1987. Difference and Domination: On Sex Discrimination. In Feminism Unmodified; Discourses on Life and Law, Harvard UP, Cambridge, 32-45. 
[33] Bernice Martin. 1984. Mother Wouldn't Like It! Housework as Magic. Theory Society and Culture 2, 2, 19-35.

[34] Michael Massimi, Jill P. Dimond and Christopher A. Le Dantec. 2012. Finding a New Normal: The Role of Technology in Life Disruptions. In Proceedings of Proceedings of the ACM 2012 conference on Computer Supported Cooperative Work. ACM, Seattle, Washington, USA, 719-728. http://dx.doi.org/10.1145/2145204.2145314

[35] L. Nader. 1992. Up the Anthropologist: Perspectives Gained from Studying Up. . In Reinventing Anthropology, Dell H. Hymes Ed. Pantheon Books, New York, 284-311.

[36] Carman Neustaedter, A. J. Bernheim Brush and Saul Greenberg. 2009. The Calendar Is Crucial: Coordination and Awareness through the Family Calendar. ACM Trans. Comput.-Hum. Interact. 16, 1, 1-48. http://dx.doi.org/10.1145/1502800.1502806

[37] J. O'Brien, Rodden, T., Rouncefield, M., and Hughes, J. . 1999. At Home with Technology: An Ethnographic Study of a Set-Top Box Trial. . ACM Transactions on $\mathrm{HCl}$ 6, 3, 282-308.

[38] Sherry Ortner. 1995. Ethnography among the Newark; the Class of '58 Weequahic High School. In Naturalizing Power; Essays in Feminist Cultural Analysis, Sylvia J. Yanagisako, and C. Delaney Ed. Routeledge, New York.

[39] Sherry Beth Ortner. 1974. Is Female to Male as Nature Is to Culture. Women, Culture and Society, 67-88.

[40] Erika Shehan Poole. 2012. Interacting with Infrastructure: A Case for Breaching Experiments in Home Computing Research. In Proceedings of Proceedings of the ACM 2012 conference on Computer Supported Cooperative Work. ACM, Seattle, Washington, USA, 759-768. http://dx.doi.org/10.1145/2145204.2145319

[41] Erika Shehan Poole. 2012. Interacting with Infrastructure: A Case for Breaching Experiments in Home Technology Research. In Proceedings of ACM CSCW 2012. ACM, Seattle, WA, USA.

[42] Erika Shehan Poole, Marshini Chetty, Rebecca E. Grinter and W. Keith Edwards. 2008. More Than Meets the Eye: Transforming the User Experience of Home Network Management. In Proceedings of Proceedings of the 7th ACM conference on Designing interactive systems. ACM, Cape Town, South Africa, 455-464. http://dx.doi.org/10.1145/1394445.1394494

[43] Erika Shehan Poole, Marshini Chetty, Tom Morgan, Rebecca E. Grinter and W. Keith Edwards. 2009. Computer Help at Home: Methods and Motivations for Informal Technical Support. In Proceedings of ACM CHI 2009. ACM, Boston, MA, USA, 739-748. http://dx.doi.org/10.1145/1518701.1518816

[44] J.A. Rodeand J.J. Kaye. 2006. Is to Nurture in Technology's Nature In Proceedings of Ubicomp.

[45] Jennifer A. Rode. 2010. The Roles That Make the Domestic Work. In Proceedings of Proceedings of the 2010 ACM conference on Computer supported cooperative work. ACM, Savannah, Georgia, USA, 381-390. http://dx.doi.org/10.1145/1718918.1718984
[46] Jennifer A. Rode. 2010. The Roles That Make the Domestic Work. In Proceedings of ACM CSCW 2010. ACM, Savannah, Georgia, USA, 381390. http://dx.doi.org/10.1145/1718918.1718984

[47] Jennifer A. Rode. 2011. A Theoretical Agenda for Feminist Hci. Interact. Comput. 23, 5, 393-400. http://dx.doi.org/10.1016/j.intcom.2011.04.005

[48] Jennifer A. Rode, Eleanor F. Toye, and Alan F. Blackwell. 2004. The Fuzzy Felt Ethnography- Understanding the Programming Patterns of Domestic Appliances. Personal and Ubiquitous Computing 8, 161176. .

[49] Jennifer Ann Rode. 2008. An Ethnographic Examination of the Relationship of Gender \\\& End-User Programming. thesis. California State University at Long Beach,

[50] Ruth Schwartz-Cowan. 1983. More Work for Mother: The Ironies of Household Technology from the Open Hearth to the Microwave. Basic Books, New York, New York.

[51] Joan W. Scott. 1988. Deconstructing Equality-Versus-Difference: Or the Usess of Postructuralist Theory for Freminism. Feminist Studies $14,1,32-50$.

[52] Timothy Sohn, Lorikeet Lee, Stephanie Zhang, David Dearman and Khai Truong. 2012. An Examination of How Households Share and Coordinate the Completion of Errands. In Proceedings of Proceedings of the ACM 2012 conference on Computer Supported Cooperative Work. ACM, Seattle, Washington, USA, 729-738. http://dx.doi.org/10.1145/2145204.2145315

[53] S. Strasser. 2000. Never Done: A History of American Housework. Holt Paperbacks,

[54] A. and J. Corbin. Strauss. 1998. Basics of Qualitative Research: Grounded Theory Procedures and Techniques. (Second Edition). Sage $P$, Thousand Oaks, CA.

[55] Peter Tolmie, James Pycock, Tim Diggins, Allan MacLean and Alain Karsenty. 2002. Unremarkable Computing. In Proceedings of Proceedings of the SIGCHI Conference on Human Factors in Computing Systems. ACM, Minneapolis, Minnesota, USA, 399-406. http://dx.doi.org/10.1145/503376.503448

[56] E. M. Trauth. 2006. Theorizing Gender and Information Technology Research. . In Encyclopedia of Gender and Information Technology, Idea Group Reference, Hershey, PA, 1154-1159. .

[57] Sherry Turkle. 1988. Computational Reticence: Why Women Fear the Intimate Machine. In Technology and Women's Voices: Keeping in Touch, Cheris Kramarae Ed. Routledge \& Kegan Paul, London, UK, 4161.

[58] Sherry Turkle, and Seymour Papert. 1990. Epistemological Pluralism: Styles and Voices within the Computer Culture. Signs 16, 1, 128-157.

[59] Ellen van Oost. 2003. Materialized Gender: How Shavers Configure the Users' Femininity and Masculinity. In How Users Matter,195-208.

[60] Amy Voida, Sheelagh Carpendale and Saul Greenberg. 2010. The Individual and the Group in Console Gaming. In Proceedings of Proceedings of the 2010 ACM conference on Computer supported 
Putting the Gender Back in Digital Housekeeping

cooperative work. ACM, Savannah, Georgia, USA, 371-380.

http://dx.doi.org/10.1145/1718918.1718983

[61] Candance West, and Sarah Fenstermaker. 1995. Doing Difference. Gender, and Society 9, 1, 8-37. 